\title{
Targeting VEGFR and FGFR in head and neck squamous cell carcinoma in vitro
}

\author{
ROMAN C. BRANDS ${ }^{1,2}$, LUISE M. KNIERIM ${ }^{1}$, FRANCESCO DE DONNO ${ }^{1}$, VALENTIN STEINACKER ${ }^{1}$, \\ STEFAN HARTMANN $^{1,3}$, AXEL SEHER ${ }^{1}$, ALEXANDER C. KÜBLER ${ }^{1}$ and URS D.A. MÜLLER-RICHTER ${ }^{1}$ \\ ${ }^{1}$ Department of Oral and Maxillofacial Plastic Surgery, University Hospital Würzburg; \\ ${ }^{2}$ Comprehensive Cancer Center Mainfranken, University Hospital Würzburg; \\ ${ }^{3}$ Interdisciplinary Center for Clinical Research, University Hospital Würzburg, \\ D-97070 Würzburg, Germany
}

Received March 13, 2017; Accepted June 6, 2017

DOI: $10.3892 /$ or.2017.5801

\begin{abstract}
Head and neck squamous cell carcinoma (HNSCC) is a heterogeneous disease characterized by a tumor microenvironment (TME) that overexpresses vascular endothelial growth factor receptor (VEGFR) and fibroblast growth factor receptor (FGFR), which can lead to neovascularization, tumor growth and metastasis. Therapeutic strategies inhibiting these signaling pathways might lead to innovative HNSCC treatments. Five HNSCC cell lines were characterized based on VEGFR1-3 and FGFR1-4 expression by sqRT-PCR and treated with three different tyrosine kinase inhibitors (TKIs) (nintedanib, dovitinib and pazopanib), all of which are effective against VEGFR and FGFR family members. Crystal violet assays were performed to analyze the effect of the treatments on cell growth (viability). Additionally, VEGFR1-3 and FGFR1-4 expression data were retrieved from The Cancer Genome Atlas (TCGA), and statistical analyses were performed to investigate the receptor expression level in the different cell lines and the efficacy of the single-agent treatments. A correlation analysis was performed to quantify the degree of relationship between receptor expression and drug efficacy. With the exception of VEGFR2, the targeted receptors were expressed at different levels in all of the cell lines. The cell lines exhibited concentration-dependent responses with cell line-specific differences toward two of the three TKIs (nintedanib and dovitinib). Notably, all of the cell lines were resistant to pazopanib. TKIs have potential as therapeutic agents for HNSCC. Cell line-specific differences were observed in our in vitro experiments. The observed pazopanib resistance could be explained by receptor
\end{abstract}

Correspondence to: Dr Roman C. Brands, Department of Oral and Maxillofacial Plastic Surgery, University Hospital Würzburg, Pleicherwall 2, D-97070 Würzburg, Germany

E-mail: brands_r@ukw.de

Key words: vascular endothelial growth factor receptor, fibroblast growth factor receptor, head and neck squamous cell carcinoma expression. Further investigation is required to determine TKI efficacy in HNSCC.

\section{Introduction}

With approximately 13,800 new cases per year in Germany and 600,000 new cases worldwide according to data from the Robert Koch Institute, head and neck squamous cell carcinoma (HNSCC) is one of the most common tumors $(1,2)$. Despite the new therapeutic and diagnostic procedures, a poor 5-year survival rate of 55-60\% has remained nearly unchanged in recent decades $(1,3)$. Infiltration of locoregional tissue and lymph node metastasis occur at a high frequency in $66 \%$ of HNSCC patients $(4,5)$. The recently approved immune checkpoint inhibitors pembrolizumab and nivolumab, which have shown antitumor efficacy in non-small-cell lung cancer (6-8), represent the few innovations in the treatment of recurrent or metastatic HNSCC during the last decades (9). However, tyrosine kinase inhibitors (TKI) are being investigated in clinical trials, some of which have shown favorable survival data (10).

Complex relationships exist between the oncogenic stroma and its surroundings in this heterogeneous disease (11). Cells from the immune system, the tumor vasculature and lymphatic systems and cancer associated fibroblasts (CAF) can encourage tumor growth, invasion and metastasis $(12,13)$. Molecules in this environment, such as vascular endothelial growth factor (VEGF) and fibroblast growth factor (FGF), stimulate the neovascularization needed for cancer growth (13).

The amplification and overexpression of FGFR1-3 have been observed in HNSCC in several studies (14-16). Fibroblast growth factors (FGF) -A, -B, -C and -D, which play key roles in embryonic development, are crucial for angiogenesis and nerve and cartilage regeneration in adult tissue $(17,18)$. Schultz-Hector and Haghayegh (19) demonstrated a correlation between FGF production in tumor cells and growth rate, making FGF a potential target in HNSCC (20).

Rapid tumor growth causes hypoxia in different areas of the malignant tissue, which is a feature of most solid tumors and is associated with reduced radiotherapy and chemotherapeutic efficacy (21). Oxygen deficiency releases signaling molecules, including VEGF, to induce vasculogenesis, which subsequently 
Table I. The targets of the tyrosine kinase inhibitors pazopanib, dovitinib and nintedanib.

Target

Drug

\begin{tabular}{|c|c|c|c|c|c|}
\hline Nintedanib & FGFR1-3 & VEGFR1-3 & PDGFR $\alpha / \beta$ & - & _ \\
\hline Dovitinib & FGFR1-3 & VEGFR1-4 & - & cKit & FLT-3 \\
\hline Pazopanib & FGFR1,3 & VEGFR1-3 & PDGFR $\alpha / \beta$ & cKit & 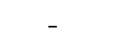 \\
\hline
\end{tabular}

correlates with faster invasion and metastasis (22). As demonstrated by Mărgăritescu and colleagues (23) VEGF is expressed in $87 \%$ of HNSCC specimens, and increased expression levels are noted in neoplastic compared with dysplastic epithelium (24). Inhibiting the expression of either the VEGFR or the ligands decreases HNSCC cell proliferation (25).

As previously mentioned, we focused on investigating multi-targeted TKIs (pazopanib, dovitinib and nintedanib), which target VEGFR and FGFR family members. Thus, we conducted the present study to investigate the efficacy of nintedanib, dovitinib and pazopanib as HNSCC treatments in vitro. To the best of our knowledge, this study constitutes the first in vitro investigation of pazopanib and nintedanib in HNSCC cell lines.

\section{Materials and methods}

The Cancer Genome Atlas (TCGA) analysis. Data of VEGFR1-3 and FGFR1-4 mRNA expression in HNSCC were retrieved from The Cancer Genome Atlas (TCGA) via cBioPortal $(26,27)$, and data from 530 cancer samples were analyzed to assess VEGFR1-3 and FGFR1-4 mutations, amplifications and gains. Cases with and without alterations were compared in terms of overall and median (months) survival.

Cell lines. The following cell lines were used: PCI-1, laryngeal carcinoma of the glottis from a male patient (pT2N0M0G2); PCI-9, primary carcinoma at the base from the tongue of a male patient (pT4N3M0G2); PCI-13, male patient who suffered from oral squamous cell carcinoma of the retromolar triangle (pT4pN1M0G3); PCI-52, primary carcinoma of the aryepiglottic fold from a male patient (pT2N0M0G2); and PCI-68, Primary tongue carcinoma from a male patient (pT4N0M0G1).

The cells were cultured at $37^{\circ} \mathrm{C}$ and $5 \% \mathrm{CO}_{2}$ in Dulbecco's modified Eagle's medium (DMEM; low-glucose medium; Invitrogen, Karlsruhe, Germany; $4.5 \mathrm{~g} / 1$ D-glucose, $4 \mathrm{mM}$ L-glutamine, $110 \mathrm{mg} / 1$ sodium pyruvate, $10 \%$ fetal calf serum (FCS) and $10.000 \mathrm{U} / \mathrm{ml}$ penicillin/streptomycin; Life Technologies, Darmstadt, Germany) and the medium was changed up to twice a week as previously described (28).

Drugs. Nintedanib (Boehringer Ingelheim Pharma GmbH \& Co. KG, Ingelheim am Rhein, Germany), dovitinib (Novartis Pharma GmbH, Nürnberg, Germany) and pazopanib (GlaxoSmithKline GmbH \& Co. KG, München, Germany) were purchased from Selleckchem (Houston, TX, USA). The targets of the drugs are presented in Table I.
Table II. The primers used for sqRT-PCR.

\begin{tabular}{clc}
\hline Primer no. & Receptor & Order code \\
\hline 1 & FGFR1_1 & QT00102837 \\
2 & FGFR2_1 & QT00098560 \\
3 & FGFR3_1 & QT01000685 \\
4 & FGFR4_1 & QT00027636 \\
5 & PDGFRA_1 & QT00012719 \\
6 & PDGFRB_1 & QT00082327 \\
7 & FLT1_1 & QT00073640 \\
8 & KDR_1 & QT00069818 \\
9 & FLT4_1 & QT00063637 \\
10 & CSF1R_1 & QT00073276 \\
11 & KIT_1 & QT00080409 \\
12 & FLT3_1 & QT00071316 \\
\hline
\end{tabular}

Crystal violet assay. After detachment with $0.25 \%$ trypsin and $0.53 \mathrm{mM}$ ethylenediaminetetraacetic acid (EDTA) from the culture flask, the cell numbers were measured using a Casy cell counter (Roche Diagnostics GmbH, Penzberg, Germany). A total of 10,000 cells/well were seeded on a 96-well plate, and after $24 \mathrm{~h}$ of incubation, the cells were exposed to various concentrations ( $\log 2$ dilutions) of nintedanib (starting concentration of $100 \mu \mathrm{M}$ ), dovitinib (starting concentration of $200 \mu \mathrm{M}$ ) and pazopanib (starting concentration of $800 \mu \mathrm{M}$ ). After $72 \mathrm{~h}$ of incubation, medium was removed, and the cells were stained with crystal violet $(0.1 \%$ crystal violet $/ 20 \%$ $\mathrm{MetOH})$ for $12 \mathrm{~min}$. Afterwards, the cells were washed with distilled water four times, and the 96-well plates were dried for $24 \mathrm{~h}$ in air. For the photometric determination, $100 \mu \mathrm{l}$ of $\mathrm{MetOH}$ was added to each well. After $10 \mathrm{~min}$, the absorbance was measured with a plate reader at $595 \mathrm{~nm}$ (Rainbow Spectra; Tecan, Maennedorf, Switzerland). Each value was measured twice and every experiment was performed in triplicate. Representative extracts from the data were obtained for this publication.

Semi-quantitative reverse transcription polymerase chain reaction ( $s q R T-P C R$ ). RNA from cell pellets was isolated using the RNeasy ${ }^{\circledR}$ Mini kit (Qiagen ${ }^{\circledR}$, Venlo, the Netherlands) following the manufacturer's instructions. The RNA concentration was determined photometrically using NanoDrop 2000 spectrophotometer (Thermo Fisher Scientific, Waltham, MA, USA) at 260/280 $\mathrm{nm}$. cDNA synthesis was performed with $1 \mu \mathrm{g}$ of RNA/probe using the QuantiTect ${ }^{\circledR}$ 
Table III. The effects of different nintedanib concentrations on the cell lines PCI-1, PCI-9, PCI-13, PCI-52 and PCI-68 by Mann-Whitney test.

Concentration $(\mu \mathrm{M})$

\begin{tabular}{|c|c|c|c|c|c|}
\hline & 0 vs. 6 & 0 vs. 13 & 0 vs. 25 & 0 vs. 50 & 0 vs. 100 \\
\hline \multicolumn{6}{|l|}{ Cell line } \\
\hline PCI-1 & $0.0022^{\mathrm{b}}$ & $0.0022^{\mathrm{b}}$ & $0.0022^{\mathrm{b}}$ & $0.0022^{\mathrm{b}}$ & $0.0022^{\mathrm{b}}$ \\
\hline PCI-9 & $0.0022^{\mathrm{b}}$ & $0.0022^{\mathrm{b}}$ & $0.0022^{\mathrm{b}}$ & $0.0022^{\mathrm{b}}$ & $0.0022^{b}$ \\
\hline PCI-13 & 0.6753 & $0.0022^{\mathrm{b}}$ & $0.0022^{\mathrm{b}}$ & $0.0022^{\mathrm{b}}$ & $0.0022^{b}$ \\
\hline PCI-52 & $0.0043^{\mathrm{a}}$ & $0.0022^{\mathrm{b}}$ & $0.0022^{\mathrm{b}}$ & $0.0022^{b}$ & $0.0022^{b}$ \\
\hline PCI-68 & $0.0043^{\mathrm{a}}$ & 0.6753 & $0.0411^{\mathrm{a}}$ & $0.0022^{\mathrm{b}}$ & $0.0022^{\mathrm{b}}$ \\
\hline
\end{tabular}

$\mathrm{P}$-values $<0.05$ are considered significant $\left({ }^{\mathrm{a}} \mathrm{P} \leq 0.05 ;{ }^{\mathrm{b}} \mathrm{P} \leq 0.01\right)$.

reverse transcription kit (Qiagen) following the manufacturer's instructions. Semi-quantitative gene expression levels were assessed via real-time polymerase chain reaction (sqRT-PCR) with the CFX96 Real-Time PCR Detection system (Bio-Rad Laboratories $\mathrm{GmbH}$, München, Germany). The amplification was performed with QuantiTect ${ }^{\circledR}$ SYBR-Green PCR kit (Qiagen) in a total volume of $25 \mu \mathrm{l} /$ probe following the manufacturer's instruction, and $1.5 \mu \mathrm{l}$ of gene-specific QuantiTect primers (Qiagen, Hilden, Germany) was added to each probe. The thermal profile was as follows: $1 \times 95^{\circ} \mathrm{C}$ for $15 \mathrm{~min}, 40 \mathrm{x} 15 \mathrm{sec}$ at $95^{\circ} \mathrm{C}, 30 \mathrm{sec}$ at $55^{\circ} \mathrm{C}$ and $30 \mathrm{sec}$ at $72^{\circ} \mathrm{C}$ ). The primers used in the present study are listed in Table II. Each value was measured twice and every experiment was performed in duplicate.

The comparative $\triangle \mathrm{CT}$ method was used for normalization of the PCR data (29). Using $\beta$-actin as a standard gene (assuming an expression level of $100 \%$ ), we quantified the expression of each gene relative to that of $\beta$-actin. The relative expression levels were classified into four different groups: very strong expression ( $\geq 0.1 \%)$; strong expression (0.01-0.09\%); intermediate expression (0.001-0.009\%); and low expression $(\leq 0.0009 \%)$.

Statistical analysis. Statistical analysis was performed using Microsoft Excel 2010 (Microsoft Corp., Redmond, WA, USA) and Prism 6.05 (GraphPad, Inc., La Jolla, CA, USA). Different experimental aspects were investigated [data derived from TCGA database $(26,27)]$. First, we examined the potency of nintedanib, dovitinib and pazopanib in single agent therapy against HNSCC in vitro. Afterwards, we compared single drug efficacy between the drugs. Following at least three experimental replicates, data were evaluated with a non-parametric Mann-Whitney test, and the significance level was set at $\mathrm{P} \leq 0.05$. A correlation analysis was performed for the variables 'receptor expression' and 'fraction of viable cells' at a specific drug concentration $(6 \mu \mathrm{M})$ (Tables I-III). The statistical analysis was based on several repeated and representative experiments.

\section{Results}

TCGA analysis. Data on VEGFR and FGFR mRNA expression in HNSCC were retrieved from TCGA. In $10 \%$ of the cases,

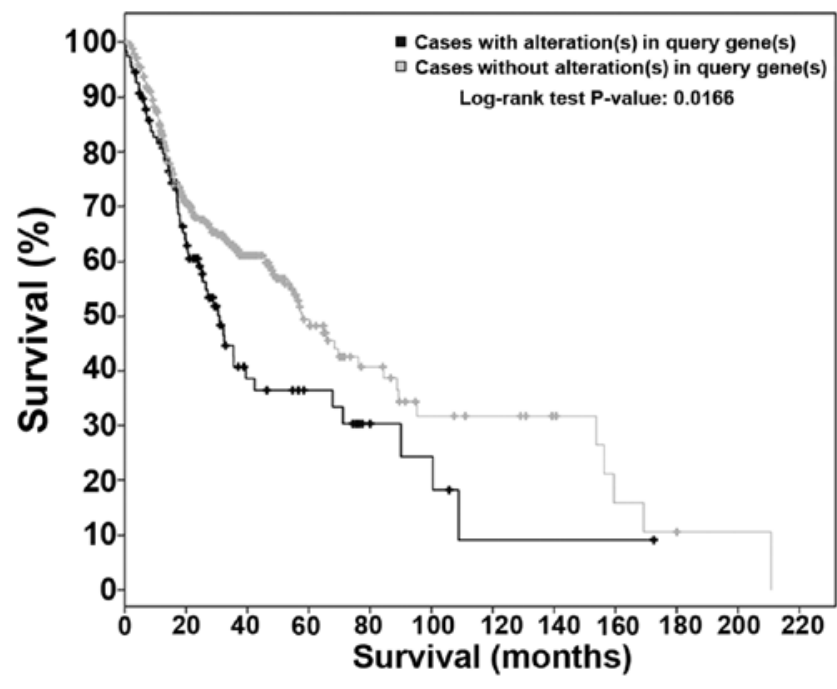

Figure 1. The Kaplan-Meier plot illustrates overall survival curves with regard to VEGFR1+3 expression in head and neck squamous cell carcinoma (HNSCC). The grey line shows cases with alterations in VEGFR1+3 expression and the black line shows the cases without alterations. A significant $(\mathrm{P}=0.0166)$ decrease in overall survival was detected in the cases with alterations [data derived from TCGA database $(26,27)]$.

a mutation, gain or amplification was detected for VEGFR1. VEGFR2 alterations were noted in $16 \%$ of the cases, whereas anomalies in VEGFR3 were detected in $9 \%$ of the cases. Thus, based on the collection of mutations, $30 \%$ overall among the cases showed alterations. VEGFR $1+3$ mutations were significantly $(\mathrm{P}=0.0166)$ decreased with increased overall survival (median survival, 57.88 vs. 30.45 months) (Fig. 1). Changes to FGFR family members were evident in $46 \%$ of the cases, whereas FGFR1 amplifications and gains were noted in $31 \%$ of patients. In addition, FGFR3 amplification, gain or mutation was noted in $12 \%$ of the cases. FGFR2 and FGFR 4 mutations were detected in 9 and $8 \%$ of the cases, respectively $(26,27)$. No significant $(\mathrm{P}=0.63)$ degree of correlation could be identified between FGFR alterations and overall survival (Fig. 2).

Expression of receptor tyrosine kinases in HNSCC cell lines. VEGFR1-3 and FGFR1-4 expression in five cell lines (PCI-1, 
Table IV. The effects of different dovitinib concentrations on the cell lines PCI-1, PCI-9, PCI-13, PCI-52 and PCI-68 by Mann-Whitney test.

Concentration $(\mu \mathrm{M})$

\begin{tabular}{lllll}
\hline 0 vs. 6 & 0 vs. 13 & 0 vs. 25 & 0 vs. 50 & 0 vs. 100
\end{tabular}

\begin{tabular}{|c|c|c|c|c|c|}
\hline \multicolumn{6}{|l|}{ Cell line } \\
\hline PCI-1 & $0.0022^{b}$ & $0.0022^{b}$ & $0.0022^{\mathrm{b}}$ & $0.0022^{\mathrm{b}}$ & $0.0022^{b}$ \\
\hline PCI-9 & $0.0152^{\mathrm{a}}$ & $0.0022^{\mathrm{b}}$ & $0.0022^{\mathrm{b}}$ & $0.0022^{\mathrm{b}}$ & $0.0022^{b}$ \\
\hline PCI-13 & $0.0022^{\mathrm{b}}$ & $0.0022^{\mathrm{b}}$ & $0.0022^{\mathrm{b}}$ & $0.0022^{\mathrm{b}}$ & $0.0022^{b}$ \\
\hline PCI-52 & $0.0022^{\mathrm{b}}$ & $0.0022^{\mathrm{b}}$ & $0.0022^{\mathrm{b}}$ & $0.0022^{\mathrm{b}}$ & $0.0022^{b}$ \\
\hline PCI-68 & $0.0022^{b}$ & $0.0022^{\mathrm{b}}$ & $0.0022^{\mathrm{b}}$ & $0.0022^{\mathrm{b}}$ & $0.0022^{b}$ \\
\hline
\end{tabular}

P-values $<0.05$ are considered significant. ( ${ }^{\mathrm{a}} \mathrm{P} \leq 0.05$; $\left.{ }^{\mathrm{b}} \mathrm{P} \leq 0.01\right)$.

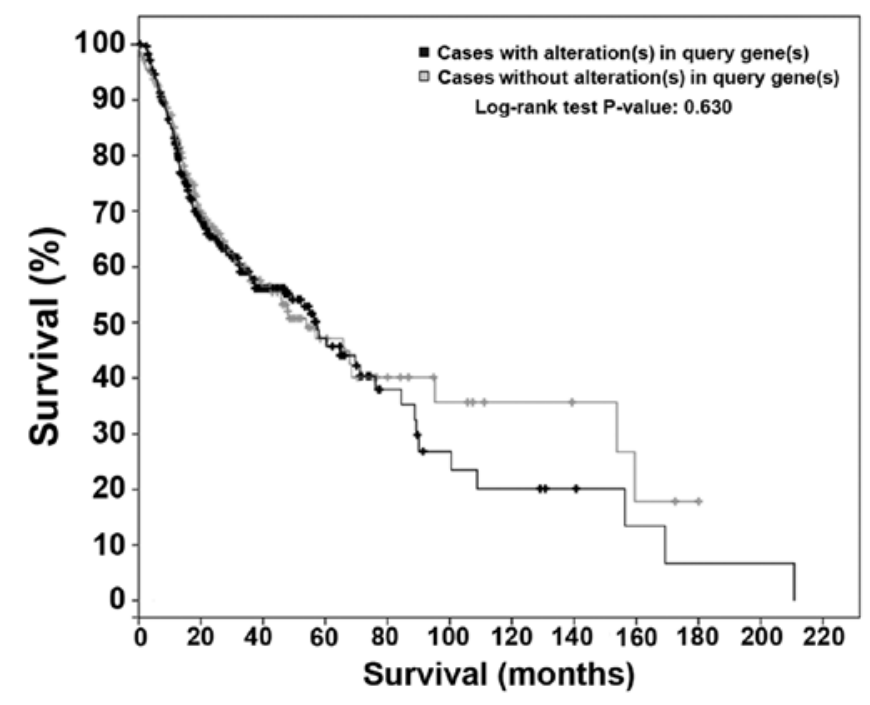

Figure 2. The Kaplan-Meier plot illustrates overall survival curves with regard to FGFR1-4 expression in head and neck squamous cell carcinoma (HNSCC). The grey line shows cases with alterations in FGFR1-4 expression, and the black line shows the cases without alterations. No significant $(\mathrm{P}=0.630)$ difference in overall survival was detected.

PCI-9, PCI-13, PCI-52 and PCI-68) was analyzed via RT-PCR. VEGFR1+3 exhibited low and intermediate expression levels in all of the cell lines, whereas VEGFR-2 was only detected at very low levels in PCI-68. FGFR1 was highly expressed in the PCI-52 and PCI-68 cell lines and exhibited low or intermediate expression in the remaining cell lines. Four of the five cell lines (PCI-1, PCI-9, PCI-52 and PCI-68) expressed high levels of FGFR-2, whereas, PCI-13 expressed an intermediate level (Fig. 3).

Impact of nintedanib treatment on HNSCC cell lines. Each cell line exhibited a concentration-dependent response toward different concentrations of nintedanib ( $\log 2$ dilution) as a monotherapy. The untreated control for each cell line was set to $100 \%$. In PCI-1, the lowest concentration of $6 \mu \mathrm{M}$ caused a cell reduction of $45 \%$ ( $\mathrm{SD} \pm 2.01 \%$ ). Maximum cell reduction was observed upon the addition of $100 \mu \mathrm{M}$ nintedanib, $12.78 \%$ $(\mathrm{SD} \pm 1.01 \%)$. The comparison of the respective concentration increases revealed highly significant differences $(\mathrm{P}=0.0022)$.
In PCI-9, a viable fraction of $57.6 \%(\mathrm{SD} \pm 6.66 \%)$ was noted for $6 \mu \mathrm{M}$ nintedanib, which was highly significant compared with the control $(\mathrm{P}<0.0022)$. The viable fraction obtained with the concentration of $13 \mu \mathrm{M}$ was $33.81 \%$ ( $\mathrm{SD} \pm 4.07 \%$ ), which was also significantly decreased $(\mathrm{P}=0.0022)$. Maximum cell reduction was detected with the highest concentration of $100 \mu \mathrm{M}$, which resulted in a $32.59 \%(\mathrm{SD} \pm 3.84 \%)$ viability decrease. Similar results were observed for cell line PCI-13. Although the viable fraction of $99.39 \%(\mathrm{SD} \pm 7.17 \%)$ at $6 \mu \mathrm{M}$ nintedanib did not exhibit significant differences compared with the control group, we found highly significant differences with the concentration increases $(\mathrm{P}=0.0022)$ and detected the lowest viable fraction of $18.37 \%(\mathrm{SD} \pm 1.61 \%)$ with the highest nintedanib concentration $(100 \mu \mathrm{M})$. In the PCI-52 cell line, we detected the first significant $(\mathrm{P}=0.0022)$ decrease in the viable fraction of $79.01 \%(\mathrm{SD} \pm 4.7 \%)$ with $13 \mu \mathrm{M}$ nintedanib. A viable fraction of $12.77 \%$ ( $\mathrm{SD} \pm 0.69 \%)$ was obtained with the highest nintedanib concentration of $100 \mu \mathrm{M}$. PCI-68 cells showed varied responsiveness to single-agent therapy with $\log 2$ dilutions of nintedanib. All concentrations $>13 \mu \mathrm{M}$ exhibited significant $(\mathrm{P}<0.05 / \mathrm{P}<0.01)$ cell count decreases compared with the control samples, and a maximum cell reduction of $39.79 \%$ ( $\mathrm{SD} \pm 3.39 \%)$ was achieved with the highest nintedanib concentration of $100 \mu \mathrm{M}$ (Fig. 4 and Table III).

Impact of dovitinib treatment on HNSCC cell lines. Each cell line exhibited varying responsiveness toward dovitinib monotherapy. The untreated control was set to $100 \%$. In the PCI-1 cell line, a high significant $(\mathrm{P}=0.0022)$ cell reduction was achieved with $6 \mu \mathrm{M}$ dovitinib. The highest cell reduction of $(19.45 \%(\mathrm{SD} \pm 3.37)$ was achieved with a concentration of $25 \mu \mathrm{M}$ dovitinib. No additional cell reduction was achieved with subsequent concentration increases to 50 and $100 \mu \mathrm{M}$. In the PCI-9 cell line, we observed a similar effect to the applied drug. A viable fraction of $75.74 \%(\mathrm{SD} \pm 11.77 \%)$ was detected with $6 \mu \mathrm{M}$ dovitinib, and a further significant $(\mathrm{P}=0.0022)$ cell reduction to $58.09 \%$ ( $\mathrm{SD} \pm 7.05 \%$ ) was observed with the next concentration increase to $13 \mu \mathrm{M}$. In addition, $25 \mu \mathrm{M}$ dovitinib decreased the viable fraction to $38.31 \%$ ( $\mathrm{SD} \pm 11.58 \%$ ). As previously demonstrated in PCI-1, no significant further cell reductions were observed with higher drug concentrations. Similar results were observed for the PCI-13 cell line. 

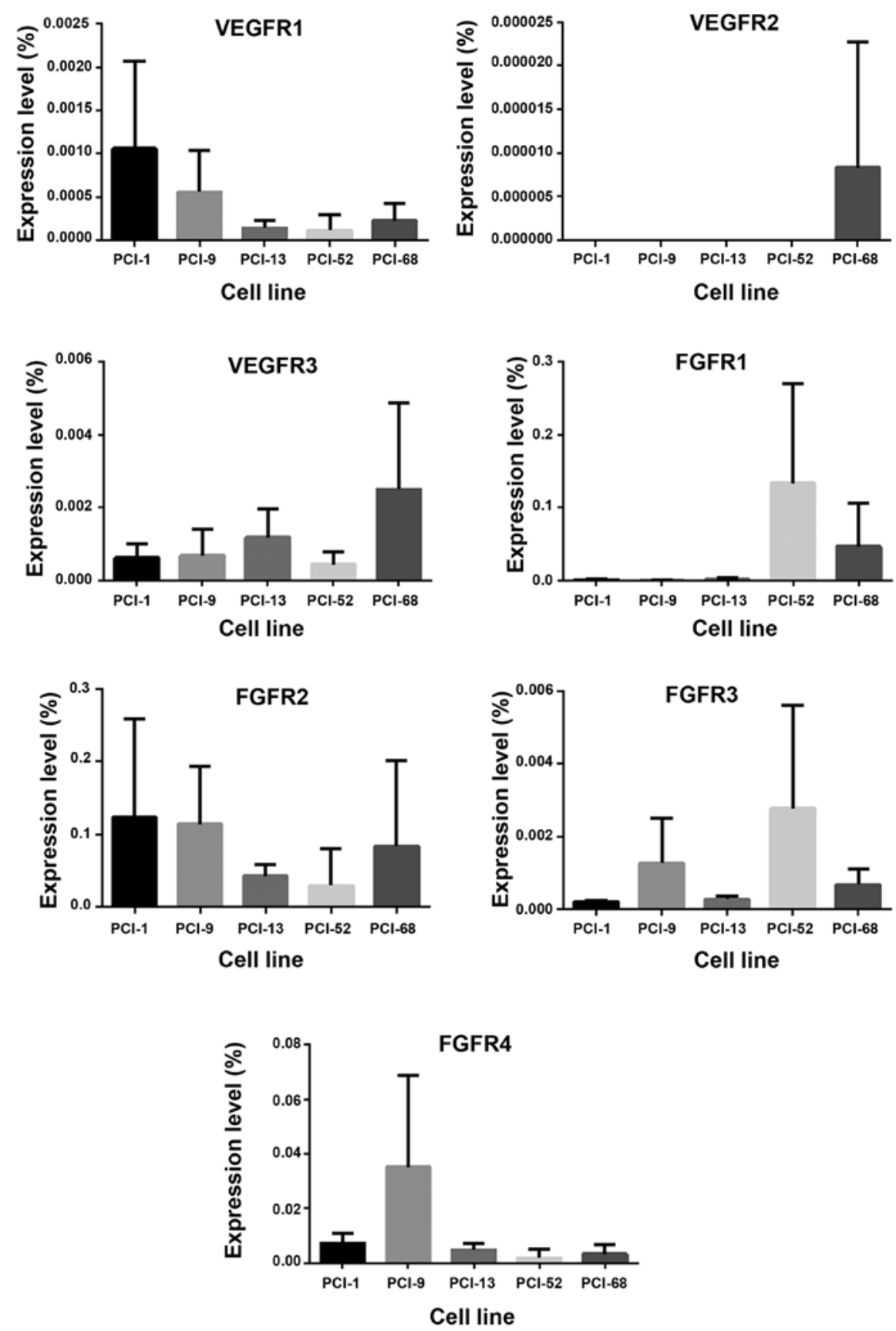

Figure 3. Representation of receptor (VEGFR1-3 and FGFR1-4) expression. The expression of the receptors is plotted on the y-axis as a percentage of the level of the housekeeping gene $\beta$-actin. The expression levels were determined as a function of PCR cycles: very strong expression $\geq 0.1$; strong expression, 0.01-0.09; intermediate expression, 0.001-0.009; and weak expression $\leq 0.0009$.

We observed significant $(\mathrm{P}=0.0022)$ cell reduction for the first three increases in concentration $(6,13$ and $25 \mu \mathrm{M})$ to viable fractions of $53.98(\mathrm{SD} \pm 4.19 \%), 44.01(\mathrm{SD} \pm 3.0 \%)$ and $10.08 \%(\mathrm{SD} \pm 1.68 \%)$, respectively. As previously noted with the PCI-1 and PCI-9 cell lines, further dovitinib concentration increases to 50 and $100 \mu \mathrm{M}$ did not lead to additional cell count reductions. A viable fraction of $74.81 \%$ $(\mathrm{SD} \pm 6.67 \%)$ was detected with $6 \mu \mathrm{M}$ dovitinib in PCI-52. Viable fractions of $69.86(\mathrm{SD} \pm 11.05 \%)$ and $32.9 \%(5.52 \%)$ were obtained with 13 and $25 \mu \mathrm{M}$ dovitinib. As previously noted for PCI-1, further significant cell viability decreases were not observed with increased dovitinib concentrations of 50 and $100 \mu \mathrm{M}$ in PCI-9 and PCI-13 cells. In PCI-68, varied responses were observed with the different dovitinib concentrations applied. A high significant $(\mathrm{P}=0.0022)$ cell reduction of $62.35 \%$ ( $\mathrm{SD} \pm 5.24 \%$ ) was noted for $6 \mu \mathrm{M}$ dovitinib, and a viable fraction of $48.89 \%$ ( $\mathrm{SD} \pm 7.83 \%$ ) was detected with $13 \mu \mathrm{M}$ dovitinib. With a concentration increase to $25 \mu \mathrm{M}$, a cell reduction to $23.02 \%$ ( $\mathrm{SD} \pm 7.68 \%$ ) was observed. Further cell reduction to $14.82 \%$ ( $\mathrm{SD} \pm 6.35 \%)$ was achieved with $100 \mu \mathrm{M}$ dovitinib, but this effect was not significant (Fig. 4 and Table IV).

Impact of pazopanib treatment on HNSCC cell lines. The cell lines exhibited a minimal response to varying concentrations of pazopanib monotherapy. In summary, we demonstrated 

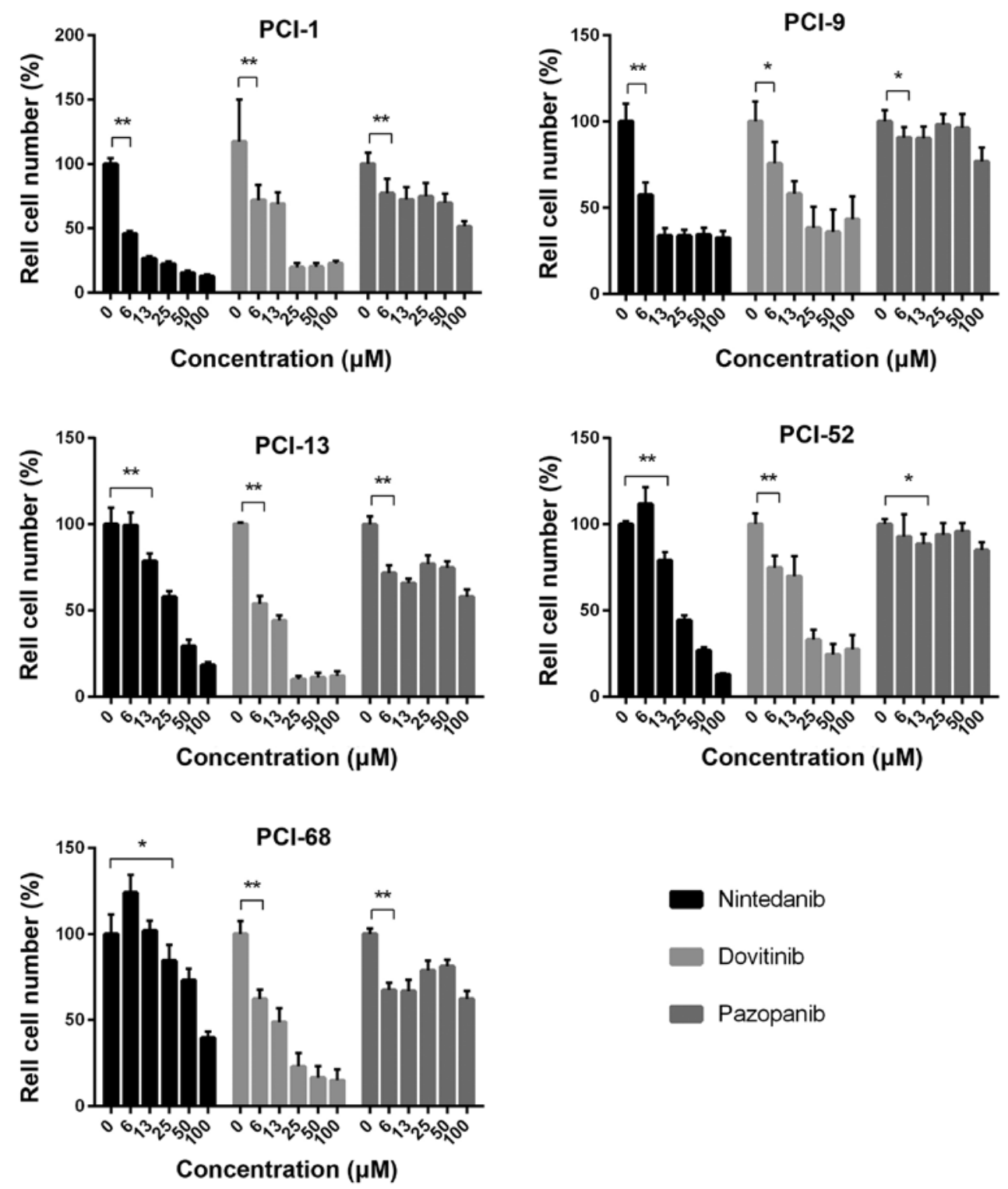

Figure 4. Treatment efficacy of nintedanib, dovitinib and pazopanib in different cell lines (PCI-1, PCI-9, PCI-13, PCI-52 and PCI-68) as measured by crystal violet assay. In all cell lines, a concentration-dependent effect of the different TKI used was detected. The horizontal bracket indicates the first concentration that yielded a significant decrease in the number of viable cells compared with the control. The data presented are shown as the means standard deviations. ${ }^{*} \mathrm{P} \leq 0.05 ;{ }^{* *} \mathrm{P} \leq 0.01$.

significant differences in the lower and upper concentration ranges for each cell line. The control was set to $100 \%$. In PCI-1, the viable fraction at $6 \mu \mathrm{M}$ pazopanib was $77.05 \%$ $(\mathrm{SD} \pm 10.63 \%)$, which was significantly different $(\mathrm{P}=0.0043)$ from the control. Similar results were noted in PCI-9, in which we detected viable fractions ranging from $90.63(\mathrm{SD} \pm 5.74 \%)$ to $76.86 \%(\mathrm{SD} \pm 7.57 \%)$. A significant difference $(\mathrm{P}=0.0411)$ was noted incubating the cells with a concentration of $6 \mu \mathrm{M}$ pazopanib. Comparing the concentrations 25 and $50 \mu \mathrm{M}$ with the control no significant differences were noted. PCI-13 exhibited varied reactions toward different pazopanib concentrations. A viable fraction of $71.73 \%$ ( $\mathrm{SD} \pm 4.22 \%$ ) was detected with $6 \mu \mathrm{M}$ pazopanib, and this effect was highly significant $(\mathrm{P}=0.0022)$ compared with the control. Incubating PCI-52 cells with a concentration of $13 \mu \mathrm{M}$ pazopanib we detected the first significant $(\mathrm{P}=0.0043)$ decrease of the cell number. No other significant differences could be detected in this cell line. In PCI-68, we detected viable fractions ranging from 81.2 $(\mathrm{SD} \pm 3.58 \%)$ to $62.46 \%$ ( $\mathrm{SD} \pm 4.33 \%$ ). Highly significant differences $(\mathrm{P}=0.0022)$ were noted for all concentrations applied by comparing with the control (Fig. 4 and Table V).

Correlation analysis. A correlation analysis was performed for the variables 'receptor expression' and 'fraction of viable cells' at a specific drug concentration $(6 \mu \mathrm{M})$ to quantify the degree of relationship between receptor expression and TKI efficacy. No significant degree of association was observed between receptor expression and TKI efficacy (data not shown).

\section{Discussion}

Squamous cell carcinoma of the head and neck is one of the most common tumor presentations worldwide (1). Therapy, which consists of surgery, radiation and systemic 
Table V. The effects of different pazopanib concentrations on the cell lines PCI-1, PCI-9, PCI-13, PCI-52 and PCI-68 by Mann-Whitney test.

Concentration $(\mu \mathrm{M})$

\begin{tabular}{lllll}
\hline 0 vs. 6 & 0 vs. 13 & 0 vs. 25 & 0 vs. 50 & 0 vs. 100
\end{tabular}

\begin{tabular}{|c|c|c|c|c|c|}
\hline \\
\hline \multicolumn{6}{|l|}{$\begin{array}{l}\text { Cell line } \\
\text { PCI-1 }\end{array}$} \\
\hline PCI-9 & $0.0411^{\mathrm{a}}$ & $0.0411^{\mathrm{a}}$ & 0.5714 & 0.5714 & $0.0022^{\mathrm{b}}$ \\
\hline PCI-13 & $0.0022^{\mathrm{b}}$ & $0.0022^{\mathrm{b}}$ & $0.0022^{\mathrm{b}}$ & $0.0022^{\mathrm{b}}$ & $0.0022^{\mathrm{a}}$ \\
\hline PCI-52 & 0.0931 & $0.0043^{b}$ & 0.0649 & 0.1797 & $0.0022^{\mathrm{b}}$ \\
\hline PCI-68 & $0.0022^{\mathrm{b}}$ & $0.0022^{\mathrm{b}}$ & $0.0022^{\mathrm{b}}$ & $0.0022^{\mathrm{b}}$ & $0.0022^{\mathrm{b}}$ \\
\hline
\end{tabular}

P-values $<0.05$ are considered significant $\left({ }^{\mathrm{a}} \mathrm{P} \leq 0.05 ;{ }^{\mathrm{b}} \mathrm{P} \leq 0.01\right)$.

chemotherapy, has changed minimally in recent years and provides a devastating 5-year survival rate of 55-60\%. Locoregional recurrence and lymph nodal metastasis are the most common mortality patterns for HNSCC and impair function and quality of life as well as overall survival $(1,3)$. The literature suggests that neoangiogenesis is one of the main reasons for this poor progress (30). Pentheroudakis et al (31) demonstrated high VEGFR1+3 transcriptional activity driven by pro-angiogenic factors at the time of relapse. Similarly, these mutations occur in relevant quantities in HNSCC and result in a significant $(\mathrm{P}=0.0166)$ decrease of overall survival (57.88 vs. 30.45 median months survival) $(26,27)$. The role of the FGFR family remains unclear. Ipenburg et al (32) demonstrated the prognostic value of FGFR1 expression in CAFs and an association with poor survival, although the literature examining the role of other family members is both limited and conflicting. Although alterations in FGFR1-4 were detected in $46 \%$ of the cases, a TCGA analysis did not reveal a significant $(\mathrm{P}=0.630)$ correlation between FGFR1-4 alterations and overall survival $(26,27)$. Given that angiogenesis plays a critical role in tumor growth in solid tumors (33) and that VEGFR-targeted therapies, such as bevacizumab, do not generate the desired effect, multi-targeted TKI might enhance therapeutic strategies for HNSCC by inhibiting several downstream targets (34).

In view of the above facts, our cell line model exhibited receptor expression patterns comparable to those detailed in the literature, and TCGA appears to be a useful method for investigating the efficacies of nintedanib, dovitinib and pazopanib for HNSCC treatment in vitro. These agents are potent VEGFR and FGFR inhibitors that exhibited different effects on different HNSCC cell lines.

Nintedanib showed a concentration-dependent efficacy in all cell lines, and a significant reduction in the viable cell fraction was observed even at the lower concentration ranges. In contrast, Kutluk Cenik et al (35) did not observe any antiproliferative effects in their in vitro investigation of lung and pancreatic cancers. However, in their in vivo models, tumor growth was inhibited in all cases (35), indicating that the tumor microenvironment might have a large impact on drug efficacy. Kudo et al (36) suggested that VEGFR2 is a feasible pharmacodynamic biomarker for hepatocellular carcinoma (HCC) in vivo, whereas the cell lines used in the present study did not show high VEGFR2 expression levels, even though significant cell count reductions were observed. A different pharmacodynamic effect might occur when treating different tumor types and cannot be excluded as a possibility, although the tumor microenvironment likely plays a crucial role during multi-targeted inhibitor therapy due to interactions with CAF. In contrast to VEGFR1+3, our TCGA data analysis did not reveal a significant correlation between VEGFR2 alteration and overall survival.

A significant decrease in the viable cell fraction was observed in response to treatment with dovitinib, even at lower concentration ranges. Because other receptors targeted by the drug are not expressed at appreciable levels, the effect is assumed to be mainly mediated through VEGFR and FGFR. Sweeny et al (11) demonstrated that dovitinib yielded significant cell count reductions in their HNSCC in vitro models. Konecny et al (37) demonstrated significant cell count reductions in endometrial cancer cell lines harboring activating FGFR2 mutations, and FGFR2 was also highly expressed in all of our cell lines. An in vivo investigation revealed significant tumor regression and growth inhibition after dovitinib treatment (38). Although our correlation analysis did not obtain a significant relationship between receptor expression and drug efficacy, the expression strength appears to play a decisive role. Furthermore, Ku (39) reported a strong interaction between dovitinib and VEGFR3, which is supported by our data.

In the tested concentration range, pazopanib showed a lack of efficacy. Although significant cell count reductions were noted for the lower concentration ranges, no further cytotoxic effects were observed. Hamberg et al (33) noted that the main target of pazopanib is VEGFR2, which was minimally expressed in our cell lines. Similar results were demonstrated by Canter et al (40) in their in vitro investigation of renal cell carcinoma (RCC) cell lines. By investigating the efficacy of two different TKIs, a cytostatic effect was noted exclusively with pazopanib. Kim et al (41) reported potent anti-tumoral activity in gastric cancer cell lines harboring FGFR2 amplification. Although FGFR2 mutations appear in only $9 \%$ of HNSCC cases, they have no significant impact on 
overall survival $(26,27)$. However, this result does not exclude potential efficacy in a clinical situation by affecting the tumor microenvironment. Importantly, a phase I clinical trial investigating the efficacies of pazopanib and cetuximab for the treatment of incurable HNSCC patients is currently under way (NCT01716416) and aims to show additive/synergistic effects in the treatment of recurrent/metastatic HNSCC. A phase II study evaluating axitinib, a multi-targeted inhibitor that mainly targets VEGFR1-3, in patients with unresectable, recurrent or metastatic head and neck cancer revealed a favorable median overall survival compared with standard therapies (10).

In conclusion, the present study demonstrated a significant decrease in cell proliferation after the in vitro treatment of HNSCC with nintedanib and dovitinib. In contrast, the cell lines appeared to be resistant to pazopanib, which could be explained by their lack of VEGFR2 expression. The results should be critically considered due to the fact that the cell lines were treated outside their normal environment resulting in a lack of interaction with surrounding tissue, blood flow or a missing supply of nutrients. Further in vivo investigation is required to determine a specific role for TKIs in HNSCC treatment.

\section{References}

1. Kamangar F, Dores GM and Anderson WF: Patterns of cancer incidence, mortality, and prevalence across five continents: Defining priorities to reduce cancer disparities in different geographic regions of the world. J Clin Oncol 24: 2137-2150, 2006.

2. Torre LA, Bray F, Siegel RL, Ferlay J, Lortet-Tieulent J and Jemal A: Global cancer statistics, 2012. CA Cancer J Clin 65: 87-108, 2015.

3. Gupta S, Kong W, Peng Y, Miao Q and Mackillop WJ: Temporal trends in the incidence and survival of cancers of the upper aerodigestive tract in Ontario and the United States. Int J Cancer 125: 2159-2165, 2009.

4. Ferlito A, Shaha AR, Silver CE, Rinaldo A and Mondin V: Incidence and sites of distant metastases from head and neck cancer. ORL J Otorhinolaryngol Relat Spec 63: 202-207, 2001.

5. Ozdek A, Sarac S, Akyol MU, Unal OF and Sungur A: Histopathological predictors of occult lymph node metastases in supraglottic squamous cell carcinomas. Eur Arch Otorhinolaryngol 257: 389-392, 2000.

6. Borghaei H,Paz-Ares L, Horn L, Spigel DR, Steins M, Ready NE, Chow LQ, Vokes EE, Felip E, Holgado E, et al: Nivolumab versus docetaxel in advanced nonsquamous non-small-cell lung cancer. N Engl J Med 373: 1627-1639, 2015.

7. Brahmer J, Reckamp KL, Baas P, Crinò L, Eberhardt WE, Poddubskaya E, Antonia S, Pluzanski A, Vokes EE, Holgado E, et al: Nivolumab versus docetaxel in advanced squamous-cell non-small-cell lung cancer. N Engl J Med 373: 123-135, 2015.

8. Reck M, Rodríguez-Abreu D, Robinson AG, Hui R, Csőszi T, Fülöp A, Gottfried M, Peled N, Tafreshi A, Cuffe S, et al; KEYNOTE-024 Investigators: Pembrolizumab versus chemotherapy for PD-L1-positive non-small-cell lung cancer. N Engl J Med 375: 1823-1833, 2016.

9. Seiwert TY, Zuo Z, Keck MK, Khattri A, Pedamallu CS, Stricker T, Brown C, Pugh TJ, Stojanov P, Cho J, et al: Integrative and comparative genomic analysis of HPV-positive and HPV-negative head and neck squamous cell carcinomas. Clin Cancer Res 21: 632-641, 2015.

10. Swiecicki PL, Zhao L, Belile E, Sacco AG, Chepeha DB, Dobrosotskaya I, Spector M, Shuman A, Malloy K, Moyer J, et al: A phase II study evaluating axitinib in patients with unresectable, recurrent or metastatic head and neck cancer. Invest New Drugs 33: 1248-1256, 2015.

11. Sweeny L,Zimmermann TM,Liu Z and Rosenthal EL: Evaluation of tyrosine receptor kinases in the interactions of head and neck squamous cell carcinoma cells and fibroblasts. Oral Oncol 48: 1242-1249, 2012.
12. Quail DF and Joyce JA: Microenvironmental regulation of tumor progression and metastasis. Nat Med 19: 1423-1437, 2013.

13. Balkwill FR, Capasso M and Hagemann T: The tumor microenvironment at a glance. J Cell Sci 125: 5591-5596, 2012.

14. Freier K, Schwaenen C, Sticht C, Flechtenmacher C, Mühling J, Hofele C, Radlwimmer B, Lichter P and Joos S: Recurrent FGFR1 amplification and high FGFR1 protein expression in oral squamous cell carcinoma (OSCC). Oral Oncol 43: 60-66, 2007.

15. Henson BJ and Gollin SM: Overexpression of KLF13 and FGFR3 in oral cancer cells. Cytogenet Genome Res 128: 192-198, 2010.

16. Wheeler SE, Shi H, Lin F, Dasari S, Bednash J, Thorne S, Watkins S, Joshi R and Thomas SM: Enhancement of head and neck squamous cell carcinoma proliferation, invasion, and metastasis by tumor-associated fibroblasts in preclinical models. Head Neck 36: 385-392, 2014.

17. Ornitz DM and Marie PJ: Fibroblast growth factor signaling in skeletal development and disease. Genes Dev 29: 1463-1486, 2015.

18. Zhao Y and Adjei AA: Targeting angiogenesis in cancer therapy: moving beyond vascular endothelial growth factor. Oncologist 20: 660-673, 2015.

19. Schultz-Hector S and Haghayegh S: Beta-fibroblast growth factor expression in human and murine squamous cell carcinomas and its relationship to regional endothelial cell proliferation. Cancer Res 53: 1444-1449, 1993.

20. Koole K, Brunen D, van Kempen PM, Noorlag R, de Bree R, Lieftink C, van Es RJ, Bernards R and Willems SM: FGFR1 is a potential prognostic biomarker and therapeutic target in head and neck squamous cell carcinoma. Clin Cancer Res 22: 3884-3893, 2016.

21. Harris BH, Barberis A, West CM and Buffa FM: Gene expression signatures as biomarkers of tumour hypoxia. Clin Oncol (R Coll Radiol) 27: 547-560, 2015.

22. Hsu HW, Wall NR, Hsueh CT, Kim S, Ferris RL, Chen CS and Mirshahidi S: Combination antiangiogenic therapy and radiation in head and neck cancers. Oral Oncol 50: 19-26, 2014.

23. Mărgăritescu C, Pirici D, Stîngă A, Simionescu C, Raica M, Mogoantă L, Stepan A and Ribatti D: VEGF expression and angiogenesis in oral squamous cell carcinoma: An immunohistochemical and morphometric study. Clin Exp Med 10: 209-214, 2010.

24. Denhart BC, Guidi AJ, Tognazzi K, Dvorak HF and Brown LF: Vascular permeability factor/vascular endothelial growth factor and its receptors in oral and laryngeal squamous cell carcinoma and dysplasia. Lab Invest 77: 659-664, 1997.

25. Tong M, Lloyd B, Pei P and Mallery SR: Human head and neck squamous cell carcinoma cells are both targets and effectors for the angiogenic cytokine, VEGF. J Cell Biochem 105: 1202-1210, 2008.

26. Cerami E, Gao J, Dogrusoz U, Gross BE, Sumer SO, Aksoy BA, Jacobsen A, Byrne CJ, Heuer ML, Larsson E, et al: The cBio cancer genomics portal: An open platform for exploring multidimensional cancer genomics data. Cancer Discov 2: 401-404, 2012.

27. Gao J, Aksoy BA, Dogrusoz U, Dresdner G, Gross B, Sumer SO, Sun Y, Jacobsen A, Sinha R, Larsson E, et al: Integrative analysis of complex cancer genomics and clinical profiles using the cBioPortal. Sci Signal 6: pl1, 2013.

28. Brands RC, Herbst F, Hartmann S, Seher A, Linz C, Kübler AC and Müller-Richter UD: Cytotoxic effects of SMAC-mimetic compound LCL161 in head and neck cancer cell lines. Clin Oral Investig 20: 2325-2332, 2016.

29. Schmittgen TD and Livak KJ: Analyzing real-time PCR data by the comparative C(T) method. Nat Protoc 3: 1101-1108, 2008.

30. Kramer B, Hock C, Birk R, Sauter A, Stuck BA, Hörmann K, Schultz JD and Aderhold C: Targeted therapies in HPV-positive and -negative HNSCC - alteration of EGFR and VEGFR-2 expression in vitro. Anticancer Res 36: 2799-2807, 2016.

31. Pentheroudakis G, Angouridakis N, Wirtz R, Nikolaou A, Kalogeras KT, Pavlidis N and Fountzilas G: Transcriptional activity of human epidermal growth factor receptor family and angiogenesis effectors in locoregionally recurrent head and neck squamous cell carcinoma and correlation with patient outcome. J Oncol 2009: 854127, 2009.

32. Ipenburg NA, Koole K, Liem KS, van Kempen PM, Koole R, van Diest PJ, van Es RJ and Willems SM: Fibroblast growth factor receptor family members as prognostic biomarkers in head and neck squamous cell carcinoma: A Systematic Review. Target Oncol 11: 17-27, 2016. 
33. Hamberg P, Verweij J and Sleijfer S: (Pre-)clinical pharmacology and activity of pazopanib, a novel multikinase angiogenesis inhibitor. Oncologist 15: 539-547, 2010.

34. Cohen EE, Davis DW, Karrison TG, Seiwert TY, Wong SJ, Nattam S, Kozloff MF, Clark JI, Yan DH, Liu W, et al: Erlotinib and bevacizumab in patients with recurrent or metastatic squamous-cell carcinoma of the head and neck: A phase I/II study. Lancet Oncol 10: 247-257, 2009.

35. Kutluk Cenik B, Ostapoff KT, Gerber DE and Brekken RA: BIBF 1120 (nintedanib), a triple angiokinase inhibitor, induces hypoxia but not EMT and blocks progression of preclinical models of lung and pancreatic cancer. Mol Cancer Ther 12: 992-1001, 2013.

36. Kudo K, Arao T, Tanaka K, Nagai T, Furuta K, Sakai K, Kaneda H, Matsumoto K, Tamura D, Aomatsu K, et al: Antitumor activity of BIBF 1120, a triple angiokinase inhibitor, and use of VEGFR2 ${ }^{+} \mathrm{pTyr}^{+}$peripheral blood leukocytes as a pharmacodynamic biomarker in vivo. Clin Cancer Res 17: 1373-1381, 2011

37. Konecny GE, Finkler N, Garcia AA, Lorusso D, Lee PS, Rocconi RP, Fong PC, Squires M, Mishra K, Upalawanna A, et al: Second-line dovitinib (TKI258) in patients with FGFR2-mutated or FGFR2-non-mutated advanced or metastatic endometrial cancer: A non-randomised, open-label, two-group, two-stage, phase 2 study. Lancet Oncol 16: 686-694, 2015.
38. Lee SH, Lopes de Menezes D, Vora J, Harris A, Ye H, Nordahl L, Garrett E, Samara E, Aukerman SL, Gelb AB, et al: In vivo target modulation and biological activity of CHIR-258, a multitargeted growth factor receptor kinase inhibitor, in colon cancer models. Clin Cancer Res 11: 3633-3641, 2005.

39. Ku X: Development and application of small molecule probes for kinase affinity purification and quantitative chemical proteomics (Thesis). In: Fakultät Wissenschaftszentrum Weihenstephan für Ernährung. Landnutzung und Umwelt Technische Universität München, München, p129, 2014. http:// docplayer.net/6560816Technische-universitat-munchen-lehrstuhl-fur-proteomik-undbioanalytik-xin-ki.html.

40. Canter D, Kutikov A, Golovine K, Makhov P, Simhan J, Uzzo RG and Kolenko VM: Are all multi-targeted tyrosine kinase inhibitors created equal? An in vitro study of sunitinib and pazopanib in renal cell carcinoma cell lines. Can J Urol 18: 5819-5825, 2011.

41. Kim ST, Jang HL, Lee SJ, Lee J, Choi YL, Kim KM, Cho J, Park SH, Park YS, Lim HY, et al: Pazopanib, a novel multitargeted kinase inhibitor, shows potent in vitro antitumor activity in gastric cancer cell lines with FGFR2 amplification. Mol Cancer Ther 13: 2527-2536, 2014. 